\title{
Salivary Sialic Acid Levels in Smokeless Tobacco Users
}

\author{
Leila Farhad Mollashahi, ${ }^{1}$ Marieh Honarmand, ${ }^{1,}$ Alireza Nakhaee, ${ }^{2}$ and Ghasem Mollashahi ${ }^{3}$ \\ ${ }^{1}$ Department of Oral Medicine, Oral and Dental Disease Research Center, School of Dentistry, Zahedan University of Medical Sciences, Zahedan, IR Iran \\ ${ }^{2}$ Department of Biochemistry, School of Medicine, Zahedan University of Medical Sciences, Zahedan, IR Iran \\ ${ }^{3}$ Zabol University of Medical Sciences, Zabol, IR Iran \\ "Corresponding author: Marieh Honarmand, Department of Oral Medicine, Oral and Dental Disease Research Center, School of Dentistry, Zahedan University of Medical \\ Sciences, Zahedan, IR Iran Tel: +98-5433229897, E-mail: honarmand56@yahoo.com
}

Received 2015 February 19; Revised 2015 April 15; Accepted 2015 May 10.

\begin{abstract}
Background: Smokeless tobacco chewing is one of the known risk factors for oral cancer. It is consumed widely by residents of southeastern Iran.

Objectives: In this study, salivary free and total sialic acid, and total protein were compared in paan consumers and non-consumers. Patients and Methods: In this cross-sectional study, unstimulated saliva of 94 subjects ( 44 paan consumers and 50 non-consumers) who were referred to the oral medicine department of the dentistry school of Zahedan were collected. Salivary free and total sialic acid, and total protein concentration were measured by standard biochemical methods, and the obtained data were analyzed using SPSS 20 through the non-parametric Mann-Whitney test.

Results: The concentration of salivary free sialic acid $(23.21 \pm 18.98 \mathrm{mg} / \mathrm{L})$ was significantly increased in paan consumers. The concentration of salivary Total sialic acid (TSA) $(39.57 \pm 26.58 \mathrm{mg} / \mathrm{L})$ and total protein $(0.77 \pm 0.81 \mathrm{mg} / \mathrm{mL})$ showed increases in paan consumers, however, the results were not statistically significant.

Conclusions: Salivary free and total sialic acid, and total protein were higher in the paan consumers compared to non-consumers. Due to the carcinogenic effect of smokeless tobacco, measurement of these parameters in saliva may be useful in early detection of oral cancer.
\end{abstract}

Keywords: Saliva, Sialic Acid, Tobacco, Smokeless

\section{Background}

There are almost 30 types of smokeless tobacco (ST), which are consumed via inhalation, chewing, sucking, or putting on the gums and teeth (1). These products include different carcinogenic compounds such as tobaccospecific nitrosamines, cadmium, lead, polonium 210, benzopyrene, and formaldehyde $(2,3)$.

The relationship between the consumption of these products and oral and laryngeal carcinoma in laboratory animals has been confirmed (4). Also, several studies have shown a relation between the users of smokeless tobacco and oral cancer (5-9).

With regard to the fact that early diagnosis is the key to the treatment of oral cancer $(9,10)$, remarkable efforts are being made to provide reliable, sensitive biochemical tests for this purpose (10). Different researchers have reported increased serum (11 - 12) and salivary $(10,13,14-15)$ sialic acid levels in oral cancer patients. Sialic acids are sugar compounds at the end of oligosaccharide chains of glycoproteins and glycolipids, which play an important role in the development of neoplastic behaviors, as important compounds of cell membranes (16).
These macromolecules play an important role in identification, impact of cells on each other and cell adhesion, which are important in the emergence of malignant transformation. Improper sialylation in cell membranes is considered an important event in the development of malignant change (10). In other words, an increased amount of sialic acid on the surface of tumor cells, and its secretion by some cells, increases its concentration in the blood or saliva (16). Several studies with contradictory results have been conducted on the serum and salivary levels of sialic acid in tobacco product consumers (16-19).

\section{Objectives}

With regard to the carcinogenic effects of ST on the oral cavity, few studies have been conducted on the salivary level of sialic acid in ST consumers as a diagnostic marker of oral cancer, the importance of early diagnosis of oral cancer, and also on the different ingredients and contents of ST, considering where the products are used. Therefore, this study aimed to assess the level of salivary sialic acid in ST consumers in southeastern Iran. 


\section{Patients and Methods}

\subsection{Participants}

In this cross-sectional study, 44 individuals consuming paan and 50 non-consumers among individuals accompanying patients referred to the Department of Oral and Maxillofacial Surgery in Zahedan Dental School from February 2012 to January 2013 were selected using the convenient sampling method. All individuals volunteered for the study and a written consent was obtained from all participants.

\subsubsection{Inclusion Criteria}

1. Willingness to participate in the study, 2. Daily consumption of a $10 \mathrm{~g}$ paan pack for at least a year by case group members.

\subsubsection{Exclusion Criteria}

1. Suffering from systemic or oral diseases, 2. Consumption of any type of medication, 3. Consumption of other tobacco products including cigarette and hookah, 4. Exposure to cigarette smoke.

\subsection{Samples}

Unstimulated saliva was collected using the spitting method. All patients were asked to refrain from eating, drinking, and brushing their teeth for 90 minutes before the sampling. All samples were collected between 9-11 Am. Individuals discharged their saliva in a pre-sterilized test tube (gamma counter)1-2 times per minute for 10 minutes in a sitting position while bending forward. The tubes were coded and sent immediately to the biochemical laboratory of Zahedan University of Medical Sciences. The samples were centrifuged at $5000 \mathrm{rpm}$ for 10 minutes. The supernatant was placed into another tube and stored at $-70^{\circ} \mathrm{C}$.

\subsection{Biochemical Analyses}

Salivary free and total sialic acid were measured using the thiobarbituric acid method introduced by Skoza et al. (20). For measurement of total sialic acid, the sample was affected by sulfuric acid $0.1 \mathrm{~N}$ at the temperature of $80^{\circ} \mathrm{C}$ for one hour. Afterwards, it was added to a periodate representative sample ( $25 \mathrm{mM}$ periodic acid in sulfuric acid $0.125 \mathrm{~N}$ ) and incubated at $37^{\circ} \mathrm{C}$ for 30 minutes. The reaction was stopped by adding $2 \%$ sodium arsenite. After disappearance of the iodine color, 0.1 M thiobarbituric acid $(\mathrm{PH}=9)$ was added to the solution. The final solution was kept at boiling temperature for 7.5 minutes. After cooling, dimethylsulphoxide was added and its absorbance was measured using a spectrophotometer(Biowave2, England) at the wavelength of $532 \mathrm{~nm}$, and the standard curve was prepared using N-acetylneuraminic acid (Sigma, St. Louis, MO, USA) as the standard. The amount of free sialic acid was determined with the same method, except hydrolysis.

The total protein was measured using the method introduced by Lowry and bovine serum albumin(Sigma) was used as the standard.

\subsection{Data Analysis}

Research data was collected and entered into SPSS 20. A non-parametric test was conducted to analyze the data after checking normality using the Kolmogorov-Smirnov test. The level of statistical significance was considered as $\mathrm{P}<0.05$.

\section{Results}

In the present study, 94 individuals were divided into consumer (44) and non-consumer (50) groups, among which $71.3 \%$ (67) were male and $28.7 \%$ (27) were female. Moreover, the average age of participants was $28.31 \pm 10.15$, and 51\% (48) were younger than 25 years old (Table 1). Obviously, there was no significant difference between the groups in their age, weight, and gender.

Data analysis using the Mann-Whitney test indicated that there was no difference in the concentration of salivary TSA and total protein between paan consumers and non-consumers. However, the concentration of free sialic acid in paan consumers was significantly higher than nonconsumers (Table 1 ).

With regard to the results, the average daily consumption of paan in consumers was $1.41 \pm 0.65$ (packs), and their consumption duration was $4.23 \pm 3.42$ (years). The results of statistical analysis regarding the level of sialic acid and the amount and duration of paan consumption are provided in Tables 2 and 3. According to the results, with an increased amount and duration of paan consumption, salivary TSA, free sialic acid, and total protein increased. These differences were significant $(\mathrm{P}<0.05)$.

\section{Discussion}

The consumption of paan (and similar compounds) is one of the health problems in Sistan and Balouchestan province in southeastern Iran. Consumption is high because of the proximity of this province with large centers for the production, export, and consumption of ST, including India and Pakistan. The illegal importation of these products in luxury packaging at a low price and similarity between the cultures and habits of inhabitants of this province with neighboring countries has created this problem. And, many consumers are unaware of the nature 
Table 1. Demographic and Salivary Free and Total Sialic Acid, and Total Protein Concentration in Subjects

\begin{tabular}{|c|c|c|c|}
\hline Variable & Paan Consumer (44) & Non-Consumer (50) & P Value \\
\hline Age, $y$ & $27.52 \pm 9.9$ & $29.5 \pm 10.3$ & 0.74 \\
\hline Weight, kg & $64.91 \pm 16.57$ & $65.92 \pm 15.23$ & 0.79 \\
\hline Gender, male/female & 10.34 & 14.36 & 0.42 \\
\hline Free sialic acid, mg/L & $23.21 \pm 18.98$ & $18.11 \pm 16.5$ & 0.001 \\
\hline TSA, mg/L & $39.57 \pm 26.58$ & $38.39 \pm 28.55$ & 0.63 \\
\hline Total protein, mg/mL & $0.77 \pm 0.81$ & $0.17 \pm 0.42$ & 0.49 \\
\hline
\end{tabular}

Table 2. Salivary Free and Total Sialic Acid, and Total Protein Concentration of Consumers According to Amount of Consumption

\begin{tabular}{|c|c|c|c|c|}
\hline \multirow{2}{*}{ Variable } & \multicolumn{3}{|c|}{ Amount of Consumption (Packs Per Day) } & \multirow{2}{*}{ PValue $^{a}$} \\
\hline & 1 Pack & 2 Packs & 3 Packs & \\
\hline Free sialic acid, mg/L & $20.94 \pm 10.71$ & $21.27 \pm 16.36$ & $23.76 \pm 21.65$ & 0.021 \\
\hline TSA, mg/L & $34.52 \pm 12.67$ & $40.09 \pm 29.89$ & $48.28 \pm 28.70$ & 0.025 \\
\hline Total protein, mg/m & $0.64 \pm 0.67$ & $0.75 \pm 0.78$ & $1.28 \pm 1.26$ & 0.001 \\
\hline
\end{tabular}

${ }^{\mathrm{a}}$ Mann-Whitney test.

Table 3. Salivary Free and Total Sialic Acid, and Total Protein Concentration of Consumers According to Duration of Consumption

\begin{tabular}{|c|c|c|c|}
\hline \multirow{2}{*}{ Group Variable } & \multicolumn{2}{|c|}{ Duration, $y$} & \multirow{2}{*}{ PValue $^{a}$} \\
\hline & Less Than 5 & More Than 5 & \\
\hline Free sialic acid, mg/L & $15.70 \pm 15.04$ & $20.76 \pm 18.01$ & .045 \\
\hline TSA, mg/L & $29.84 \pm 21.95$ & $39.56 \pm 27.84$ & .001 \\
\hline Total protein, $\mathbf{m g} / \mathbf{m L}$ & $1.04 \pm 0.51$ & $1.45 \pm 0.71$ & .036 \\
\hline
\end{tabular}

and side effects of these products, which lays the groundwork for this problem. Paan includes several carcinogenic compounds, including tobacco-specific nitrosamine (TSNAs), arecoline, and reactive oxygen species. Tumors have developed in different organs of laboratory animals due to the consumption of gutkha and paan masala. Using these compounds in the diet of Swiss mice resulted in the development of tumors in their lungs, stomach, liver, testicles, ovaries, and adrenal glands (21). Betel quid, with or without tobacco, and areca nut are classified by the International Agency for Research on Cancer as compounds "carcinogenic to humans" (22). Their consumption is also related to oral and pancreatic cancer, periodontal disease, cardiovascular disease, and exacerbation of asthma attacks (23). In addition, serum TSA is used as tumor marker in different cancers such as colorectal, prostate, and breast cancers (17). Increased serum (11-12) and salivary (10, 13, 1415) sialic acids levels have also been reported in oral cancer patients. An increased concentration of sialic acids in tumor cells, and its secretion by some of these cells, increases its concentration in the blood or saliva $(16,17)$. Therefore, the assessment of the level of glycoconjugates can be useful in early diagnosis and staging of oral cancer, which is often related to the consumption of ST and cigarettes (16). The consumption of tobacco products, including ST, is also considered as a risk factor for cardiovascular diseases (23, 25).

Moreover, an increased level of salivary TSA is reportedly a reflector of the risk of cardiovascular diseases in ST consumers and smokers. Although the reason for the relationship between TSA and cardiovascular diseases has not been identified, it can be said that a high salivary TSA level is caused by sialylated glycoproteins of acute phase proteins, including $\alpha 1$-acid glycoprotein, $\alpha 1$-antitrypsin, $\alpha 1$ antichymotrypsin, and ceruloplasmin (17).

The results of this study indicated that although the av- 
erage concentration of salivary TSA is higher in paan consumers compared to non-consumers, this difference is not statistically significant. Several studies with contradictory results have been conducted in this area. However, it is hard to compare the results of the present study with those of other studies due to the consumption of a different type of tobacco and the difference in duration and amount of consumption, the age of participants, the biomarker measurement method, and sample type (blood or saliva), which is one of the limitations of this study. However, the results of the present study are consistent with those by Kurtul et al. (18), whose results showed no significant statistical difference was observed between the level of salivary sialic acid in smokers and non-smokers. Joshi and Patil found no relationship between the habits of chewing tobacco and betel nut, or smoking and drinking alcohol, and the level of serum TSA (24).

The results of present study are inconsistent with those of another study conducted by Kurtul. In two different studies, Kurtul et al. measured the level of serum and salivary TSA in the consumers of a type of ST called maras powder $(16,17)$. In these studies, the level of serum and salivary TSA was higher in maras powder consumers compared to the control group. The reason for the differences in the results of these studies compared with the present study is probably the use of nicotiana rustica linn (NRL) tobacco in maras powder, which includes 6 - 10 times more nicotine than the nicotiana tobacum tobacco used in cigarettes and chewing tobacco $(16,17)$. Nicotine in tobacco can cause oxidative stress in cells (17), so it can be said that the higher the nicotine content, the higher the level of oxidative stress. According to a report by Goswami et al. (26), there are significant associations between protein-bound sialic acid and oxidative stress Therefore, increased salivary TSA is justified in the consumers of this type of ST.

The results of a study by Vajaria et al. (13) are inconsistent with those of our study. In their study, the serum and salivary TSA of tobacco consumers in the control group and patients with oral cancer was higher than non-consumers. The older age of its participants could be the reason for the different results of the aforementioned study.

Regarding salivary free sialic acid, our results were consistent with a study by Trivedi (10), although that study was conducted in patients with oral cancer who consumed tobacco, so it is difficult to compare results.

In the present study, the level of salivary TSA increases with an increased amount and duration of paan consumption, which is consistent with the results of the study by Kurtul (17). In the aforementioned study, increased TSA had a significant relationship with duration and amount of consumption.

Finally, it can be said that the investigation of the saliva of smokeless tobacco consumers can be helpful as a new method for early diagnosis and effective treatment of oral cancer.

According to our research results, the levels of salivary total sialic acid and total protein in paan consumers were higher than non-consumers, but these differences were not significant. Moreover, a positive relationship was observed between the salivary parameters and the amount and duration of paan consumption.

A study with a larger sample size is suggested to be conducted on the effect of different tobacco-containing and non-tobacco chewing compounds on serum and salivary glycoconjugates.

\section{Acknowledgments}

The authors acknowledge their gratitude to the research deputy of Zahedan University of Medical Sciences for approval and financial support of the current study.

\section{Footnotes}

Authors' Contribution: Leila Farhad Mollashahi: study concept and supervision; Marieh Honarmand: interpretation of data; Alireza Nakhaee: chemical analysis, Ghasem Mollashahi: data collection.

Funding/Support: Zahedan University of Medical Sciences.

\section{References}

1. Kaduri P, Kitua H, Mbatia J, Kitua AY, Mbwambo J. Smokeless tobacco use among adolescents in Ilala Municipality, Tanzania. Tanzan J Health Res. 2008;10(1):28-33. [PubMed: 18680962].

2. Rodu B, Jansson C. Smokeless tobacco and oral cancer: a review of the risks and determinants. Crit Rev Oral Biol Med. 2004;15(5):252-63. [PubMed: 15470264].

3. Farhadmollashahi L, Noroozifar M, Afroughe A, Hashemi ES, Honarmand M. An analytical study on the common type of smokeless tobacco available in the Iranian market. Int J High Risk Behav Addict 2014;3(4):e22133. doi: 10.5812/ijhrba.22133. [PubMed: 25741484].

4. Hoffmann D, Brunnemann KD, Prokopczyk B, Djordjevic MV. Tobaccospecific N-nitrosamines and Areca-derived N-nitrosamines: chemistry, biochemistry, carcinogenicity, and relevance to humans. J Toxicol Environ Health. 1994;41(1):1-52. doi: 10.1080/15287399409531825. [PubMed: 8277523].

5. Khawaja MR, Mazahir S, Majeed A, Malik F, Merchant KA, Maqsood M, et al. Chewing of betel, areca and tobacco: perceptions and knowledge regarding their role in head and neck cancers in an urban squatter settlement in Pakistan. Asian Pac J Cancer Prev. 2006;7(1):95-100. [PubMed: 16629524].

6. Kumar A, Sinha S, Sumit K, Saran A. A study on knowledge, attitude and practices regarding smokeless tobacco use among adult (more than eighteen years) in the rural area of jharkhand. Int. J Basic Appl. Med.Sc. 2013;3(2):378-38. 
7. Raute LJ, Sansone G, Pednekar MS, Fong GT, Gupta PC, Quah AC, et al. Knowledge of health effects and intentions to quit among smokeless tobacco users in India: findings from the International Tobacco Control Policy Evaluation (ITC) India Pilot Survey. Asian Pac J Cancer Prev. 2011;12(5):1233-8. [PubMed: 21875273].

8. Choudhury CR, Chowdhury A, Prasad RB, Shibahara T. Khaini chewing damages chromosomes 2q, 3p and 21q: occurrence in a South Asian population. Asian Pac J Cancer Prev. 2009;10(4):715-6. [PubMed: 19827902].

9. Masthan KM, Babu NA, Dash KC, Elumalai M. Advanced diagnostic aids in oral cancer. Asian Pac J Cancer Prev. 2012;13(8):3573-6. [PubMed: 23098535].

10. Trivedi DJ, Trivedi CH, Hallikeri K, Udupa R. Salivary sialic Acid As Marker of oral cancer. Int j Sci Inn Tech. 2012;1(1):48-50.

11. Rasool M, Khan SR, Malik A, Khan KM, Zahid S, Manan A, et al. Comparative Studies of Salivary and Blood Sialic Acid, Lipid Peroxidation and Antioxidative Status in Oral Squamous Cell Carcinoma (OSCC). Pak J Med Sci. 2014;30(3):466-71. doi: 10.12669/pjms.303.4985. [PubMed: 24948960].

12. Dhakar N, Astekar M, Jain M, Saawarn S, Saawarn N. Total sialic acid, total protein and total sugar levels in serum and saliva of oral squamous cell carcinoma patients: A case control study. Dent Res J (Isfahan). 2013;10(3):343-7. doi: 10.4103/1735-3327.115155. [PubMed: 24019802].

13. Vajaria BN, Patel KR, Begum R, Shah FD, Patel JB, Shukla SN, et al. Evaluation of serum and salivary total sialic acid and alpha-lfucosidase in patients with oral precancerous conditions and oral cancer. Oral Surg Oral Med Oral Pathol Oral Radiol. 2013;115(6):764-71. doi:10.1016/j.0ooo.2013.01.004. [PubMed: 23570662].

14. Dadhich M, Prabhu V, Pai VR, D'Souza J, Harish S, Jose M. Serum and salivary sialic acid as a biomarker in oral potentially malignant disorders and oral cancer. Indian J Cancer. 2014;51(3):214-8. doi 10.4103/0019-509X.146720. [PubMed: 25494107].

15. Sanjay PR, Hallikeri K, Shivashankara AR. Evaluation of salivary sialic acid, total protein, and total sugar in oral cancer: a preliminary report. Indian J Dent Res. 2008;19(4):288-91. [PubMed: 19075429].

16. Kurtul N, Cil MY, Pacaci SD. Serum total sialic acid levels in smokers and users of smokeless tobacco in form of oral powder (Maras powder). J Biomed Sci. 2005;12(3):559-63. doi: 10.1007/s11373-005-4563-x. [PubMed: 15959629].
17. Kurtul N, Gokpinar E. Salivary lipid peroxidation and total sialic acid levels in smokers and smokeless tobacco users as Maras powder. Mediators Inflamm. 2012;2012:619293. doi: 10.1155/2012/619293. [PubMed: 22577253].

18. Kurtul N, Cil MY, Bakan E. The effects of alcohol and smoking on serum, saliva, and urine sialic acid levels. Saudi Med J. 2004;25(12):1839-44. [PubMed: 15711651].

19. Avsar A, Darka O, Bodrumlu EH, Bek Y. Evaluation of the relationship between passive smoking and salivary electrolytes, protein, secretory IgA, sialic acid and amylase in young children. Arch Oral Biol. 2009;54(5):457-63. doi: 10.1016/j.archoralbio.2009.01.017. [PubMed: 19249013].

20. Skoza L, Mohos S. Stable thiobarbituric acid chromophore with dimethyl sulphoxide. Application to sialic acid assay in analytical deO-acetylation. Biochem J. 1976;159(3):457-62. [PubMed: 1008810].

21. Nair U, Bartsch H, Nair J. Alert for an epidemic of oral cancer due to use of the betel quid substitutes gutkha and pan masala: a review of agents and causative mechanisms. Mutagenesis. 2004;19(4):251-62. [PubMed: 15215323].

22. Kampangsri W, Vatanasapt P, Kamsa-Ard S, Suwanrungruang K, Promthet $\mathrm{S}$. Betel quid chewing and upper aerodigestive tract cancers: a prospective cohort study in khon kaen, Thailand. Asian Pac J Cancer Prev. 2013;14(7):4335-8. [PubMed: 23991999].

23. Banerjee SC, Ostroff JS, Bari S, D'Agostino TA, Khera M, Acharya S, et al. Gutka and Tambaku Paan use among South Asian immigrants: a focus group study. J Immigr Minor Health. 2014;16(3):531-9. doi: 10.1007/s10903-013-9826-4. [PubMed: 23579964].

24. Joshi M, Patil R. Estimation and comparative study of serum total sialic acid levels as tumor markers in oral cancer and precancer. J Cancer Res Ther. 2010;6(3):263-6. doi: 10.4103/0973-1482.73339. [PubMed: 21119250].

25. Erhardt L. Cigarette smoking: an undertreated risk factor for cardiovascular disease. Atherosclerosis. 2009;205(1):23-32. doi: 10.1016/j.atherosclerosis.2009.01.007. [PubMed: 19217623].

26. Goswami K, Nandeesha H, Koner BC, Nandakumar DN. A comparative study of serum protein-bound sialic acid in benign and malignant prostatic growth: possible role of oxidative stress in sialic acid homeostasis. Prostate Cancer Prostatic Dis. 2007;10(4):356-9. doi: 10.1038/sj.pcan.4500965. [PubMed: 17404581]. 